\title{
Structure-property studies on the antioxidant activity of flavonoids present in diet
}

\author{
Susana Teixeira ${ }^{\mathrm{a}}$, Christophe Siquet ${ }^{\mathrm{a}}$, Carla Alves $^{\mathrm{b}}$, Isabel Boal ${ }^{\mathrm{b}}$, M. Paula Marques ${ }^{\mathrm{c}}$, \\ Fernanda Borges ${ }^{\mathrm{d}, *}$, José L.F.C. Lima ${ }^{\mathrm{a}}$, Salette Reis ${ }^{\mathrm{a}, *}$ \\ ${ }^{a}$ REQUIMTE, Departamento de Química-Física, Faculdade de Farmácia, Universidade do Porto, Porto, Portugal \\ ${ }^{\mathrm{b}}$ Departamento de Química, Universidade de Aveiro, Aveiro, Portugal \\ 'Unidade "Química-Física Molecular", Departamento de Bioquímica, Faculdade de Ciências e Tecnologia, Universidade de Coimbra, Coimbra, Portugal \\ ${ }^{\mathrm{d}}$ Unidade "Química-Física Molecular", Departamento de Química Orgânica, Faculdade de Farmácia, Universidade do Porto, Porto, Portugal
}

Received 19 January 2005; revised 25 May 2005; accepted 31 May 2005

\begin{abstract}
The screening of natural flavonoids for their bioactivity as antioxidants is usually carried out by determinination of their profile as chainbreaking antioxidants, by the evaluation of their direct free radical-scavenging activity as hydrogen- or electron-donating compounds. Since this may not be the only mechanism underlying the antioxidant activity it is important to check the ability of these compounds to act as chelators of transition metal ions. Accordingly, in the present study the acidity constants of catechin and taxifolin, as well as the formation constants of the corresponding copper (II) complexes, were investigated by potentiometry and/or spectrophotometry. Moreover, a detailed quantitative examination of the coordination species formed is presented. In addition, the partition coefficients of both catechin and taxifolin in a biomimetic system (micelles) were determined, since these properties may also contribute to the antioxidant behavior of this type of compound. The $\log P$ values determined depend on the electrostatic interactions of the compounds with the differently charged micelles (the highest values were obtained for zwitterionic and cationic micelles). The prooxidant behavior of the compounds was assessed through the oxidation of 2'-deoxyguanosine, induced by a Fenton reaction, catalyzed by copper. The data obtained reveal that the flavonoids under study did not present prooxidant activity, in this particular system. The results obtained are evidence of a clear difference among the $\mathrm{p} K_{\mathrm{a}}$, the complexation properties, and the lipophilicity of the flavonoids studied, which can partially explain their distinct antioxidant activity. The most stable geometries of the free compounds were determined by theoretical (ab initio) methods, in order to properly account for the electron correlation effects which occur in these systems, thus allowing a better interpretation of the experimental data.
\end{abstract}

(C) 2005 Elsevier Inc. All rights reserved.

Keywords: Flavonoids; Catechin; Taxifolin; Antioxidant activity; Acidity constants; Ab initio calculations; Formation constants; Copper (II); Partition coefficients

Abbreviations: SPAR, structure-property-activity relationships; $2^{\prime}-\mathrm{dG}$, 2'-deoxyguanosine; 8-OH-2'dG, 8-hydroxy-2'-deoxyguanosine; CTAB, cetyltrimethylammonium bromide; SDS, sodium dodecyl sulfate; HDPC, hexadecylphosphocholine; DFT, density functional theory.

* Corresponding authors. Salette Reis is to be contacted at fax: +351222003977 .

E-mail addresses: fborges@ff.up.pt (F. Borges), shreis@ff.up.pt (S. Reis).

\section{Introduction}

Bioflavonoids are secondary phenolic plant metabolites distributed widely in nature and present in fruits, vegetables, and beverages. Apart from the purely academic study of their natural occurrence, distribution, biosynthesis, metabolism, and function in plants, flavonoids are becoming of increasing importance in applied science. Although a plethora of biological actions has been ascribed to this kind of compound, their antioxidant activity, in particular, has recently attracted much attention [1-5]. Numerous studies 
have been reported on dietary flavonoids, which are expected to have an important role in the prevention of coronary heart disease, cancer, and age-dependent neuropathologies [6-9]. Flavonoids are described as hydrogendonating antioxidants by virtue of the reducing properties of the multiple hydroxyl groups attached to aromatic ring systems, along with their ability to delocalize the resulting phenoxyl radical within the structure. It is recognized that polyphenolic flavonoids are able to scavenge different reactive oxygen radicals, such as the hydroxyl and superoxide radicals [10-12].

Considerable attention has lately been focused on the role and mechanism of action of polyphenolic compounds, namely through their ability to chelate transition metals ions. Transitions metals (especially iron and copper) are known catalysts of deleterious radical processes. Their reduced forms $\left(\mathrm{Fe}^{2+}, \mathrm{Cu}^{+}\right)$can promote the formation of hydroxyl radicals through the Fenton reaction, for example. Under normal conditions, transition metals almost do not exist freely in body fluids but are sequestered in proteins. However, in adverse circumstances this equilibrium can be broken, and the effect of antioxidant endogenous defenses and dietary polyphenols could be beneficial [13].

Copper, in particular, is a physiologically important redox-active metal that is known to be associated with endogenous oxidative damage, which likely involves the initial reduction of $\mathrm{Cu}(\mathrm{II})$ to $\mathrm{Cu}(\mathrm{I})$ by a variety of mechanisms [14].

The antioxidant and/or antiradical activity of flavonoids has been studied in different model systems, although very few studies have been performed to date to gain an insight on the structure-property-activity relationships (SPAR). In fact, this may be a rather efficient approach for the design and development of new antioxidant agents and/or for the understanding of their mechanism of action. A structureantioxidant-activity relationship of flavonoids (quercetin, rutin, kaempferol, and luteolin) has been proposed by Brown et al. [15]. A correlation was established between the structure of the flavonoids and their antioxidant activities with quercetin being the best antioxidant due mainly to the presence of a catechol group in ring B and a 3hydroxy group in ring $\mathrm{C}$. The lipophilicity of the com- pounds was also evaluated and correlated with the antioxidant activity of the flavonoids.

Accordingly, the intrinsic properties of phenolic dietary antioxidants must be evaluated, in order to correlate these parameters with their activity or side effects (such as prooxidant activity) [16-20]. Antioxidants are often capable, according to their redox potential, of reducing transition metals and therefore allowing them to catalyze oxidative damage. This prooxidant activity happens mostly at low antioxidant concentrations.

Moreover some details on the mechanism of action of dietary compounds could be obtained which could allow the establishment of a suitable database for the discovery of the pharmacophore (or toxicophore) of this type of compounds.

The aim of the present study is to gain an insight into the antioxidant and/or prooxidant activity of structurally related phenolic compounds, such as the flavonoids present in the diet, mostly in grapes and wine, through the evaluation of their physicochemical properties. Given that flavonoids could compete for the complexation of transition metals with endogenous complexing agents and induce radical damage by generating a reduced form of the metal, and that their antioxidant properties are related to their lipophilicity/ hydrophilicity according to the target system, it is important to quantify their complexation and partition capacities. Since information in this particular area of research is scarce and not fully understood, it is of the utmost importance to determine the physicochemical characteristics of phenolic compounds, mainly those that are intrinsically related to an oxidative behavior. Even though more than 4000 different flavonoids are found in nature [2], the present research is focused on two particular flavonoid structures, catechin and taxifolin, which belong to the subgroups of the flavanols and flavanones, respectively (Scheme 1). These specific flavonoids were chosen for their interesting structures, when compared to quercetin. They lack a 2,3-double bond isolating electronically the catechol group from the rest of the molecule. Therefore the influence of the catechol on the complexation toward copper can be assumed to be similar for both flavonoids. So, the results obtained can be ascribed to their only structural difference, the carbonyl group. The specific flavonoids were found in significant quantities (as monomeric species) in both fruits and wine, and taxifolin,

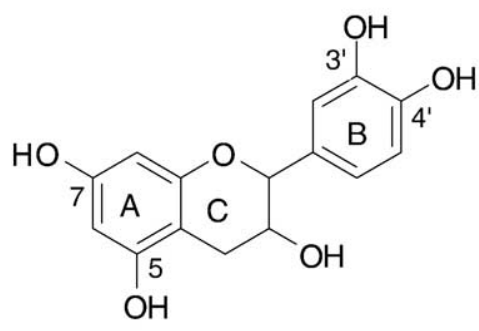

Catechin<smiles>O=C1c2c(O)cc(O)cc2OC(c2ccc(O)c(O)c2)C1O</smiles> 
in particular, is also described as a precursor of the wellknown silybin, a natural compound of therapeutic relevance [21].

The dissociation constants and chelating activity toward $\mathrm{Cu}(\mathrm{II})$ of the flavonoids presently investigated were evaluated, through potentiometry and spectrophotometry, and the experimental data were analyzed. Prooxidant behavior of the compounds was assessed through the oxidation of $2^{\prime}$-deoxyguanosine, induced by a Fenton reaction assay. Catechol, resorcinol, and trolox were introduced in this experiment for comparison. $\mathrm{Ab}$ initio molecular orbital calculations (based on the density functional theory approximation) were also performed, in order to understand the structural behavior of the compounds and to achieve a better explanation of the experimental data. As the accessibility of the antioxidant to its biological site of action is a quite important parameter-defined by the lipophilicity or hydrophilicity of the compound-the corresponding partition coefficients were also evaluated, at physiological $\mathrm{pH}$, using biomimetic systems (micelles) instead of the classic octanol/water model. In order to illustrate the effect of the different exposed surroundings on these partition coefficients, three differently charged surfactants (cationic, anionic, and zwitterionic) were used.

\section{Materials and methods}

\section{Reagents and solutions}

The flavonoids (catechin and taxifolin), $2^{\prime}$-deoxyguanosine $\left(2^{\prime}-\mathrm{dG}\right), 8$-hydroxy-2'-deoxyguanosine (8-OH-2'dG), cetyltrimethylammonium bromide (CTAB), sodium dodecyl sulfate (SDS) and hexadecylphosphocholine (HDPC), were purchased from Sigma and used without further purification. Catechol, resorcinol, and trolox were obtained from Aldrich. The copper (II) nitrate was obtained from Orion. All the other chemicals were from Merck (grade pro-analysis). Solutions were prepared with double deionized water (conductivity less than $0.1 \mu \mathrm{S} \mathrm{cm}{ }^{-1}$ ).

\section{Potentiometric measurements}

Potentiometric measurements were carried out with a Crison 2002 pH meter and 2031 burette, controlled by a personal computer, which was also used for data treatment. The electrode assembly was made up of an Orion 900029/4 AgCl/Ag reference electrode and a Russell SWL glass electrode. System calibration was performed according to the Gran method [22] in terms of hydrogen ion concentration using strong acid/strong base titrations

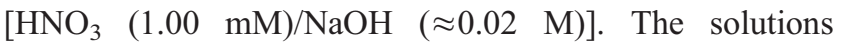
having an ionic strength of $0.10 \mathrm{M}$ were adjusted with potassium nitrate. Titrations were always carried out under a nitrogen atmosphere at $25^{\circ} \mathrm{C}$ in a double-walled glass cell.

\section{Spectrophotometric measurements}

For the determination of acidity constants by spectrophotometry an automatic spectrophotometric system was designed in order to retrieve UV/Vis spectra of the samples, at different $\mathrm{pH}$ values. Volumes of a strong base $(\mathrm{NaOH})$ were added automatically by a microburette to titrate an acidic solution of the compound under study. A peristaltic pump allowed the circulation of the solution from the reaction pot, through a flow cell of the spectrophotometer and back to the reaction pot. An UV/Vis spectrum was recorded by an Hitachi U-2000 spectrophotometer, after each addition of the base, at a stable $\mathrm{pH}$. The electrode system for $\mathrm{pH}$ measurements was calibrated according to the method described above.

For the evaluation of partition coefficients all absorption spectra were recorded at $25.0 \pm 0.1^{\circ} \mathrm{C}$ on a Perkin Elmer Lambda $45 \mathrm{UV} / \mathrm{VIS}$ spectrophotometer, for a spectral range of 200 to $400 \mathrm{~nm}$, using 1.0-nm intervals. Quartz cells with a $1-\mathrm{cm}$ path length were used. The temperature was kept constant by circulating thermostated water in the cell holder.

\section{Potentiometric determination of acidity and stability constants}

The acidity constants of the compounds were obtained by titrating $20.00 \mathrm{~mL}$ of acidified solutions $(1.00 \mathrm{mM}$ $\left.\mathrm{HNO}_{3}\right)$ of the flavonoids $(1.00 \mathrm{mM})$ with sodium hydroxide $(\approx 0.02 \mathrm{M})$. The stability constants of the ligand-copper (II) complexes were determined by titrating $20.00 \mathrm{~mL}$ of aqueous solutions of flavonoids $(1.00 \mathrm{mM})$, nitric acid (1.00 mM), and copper (II) nitrate $(1.00 \mathrm{mM})$ with sodium hydroxide $(\approx 0.02 \mathrm{M})$. For all solutions, the ionic strength was adjusted to $0.1 \mathrm{M}$ with potassium nitrate. A system calibration was performed before each determination. Evaluation of acidity and stability constants of both ligands and metal-ligand complexes was performed with data obtained from at least six independent titrations, each with more than 30 points. The experimental titration data were analyzed using the computer programs Superquad [23] and Best [24] The reported errors were calculated by the method of Albert and Serjeant [25], as the maximum difference between the logarithm of the average of the antilogarithms of the calculated $\mathrm{p} K_{\mathrm{a}}$ and $\mathrm{p} K_{\mathrm{d}}$ values and their individual values.

\section{Spectrophotometric determination of acidity constants}

Acidity constants of taxifolin were obtained using the automatic titrating spectrophotometer described above. All solutions had an ionic strength adjusted to $0.10 \mathrm{M}$ with $\mathrm{NaCl}$. Volumes of $\mathrm{NaOH}$ ( 3 to $30 \mu \mathrm{L}, 0.1 \mathrm{M}$ ) were added to a solution of taxifolin $(25 \mathrm{~mL}, 0.1 \mathrm{mM})$ of $\mathrm{pH}$ adjusted to 4 with concentrated $\mathrm{HCl}$. Spectra were recorded between 200 and $400 \mathrm{~nm}$ every $2 \mathrm{~nm}$ after each addition of the titrant. The acidity constants were calculated with the program 
SQUAD [23] by using data from at least two independent experiments, each one with more than eight spectra.

\section{2'-Deoxyguanosine oxidation assay}

The reaction mixtures $(1.5 \mathrm{~mL})$ containing $2^{\prime}-\mathrm{dG}(1 \mathrm{mM})$, potassium phosphate buffer $(20 \mathrm{mM}, \mathrm{pH} 7.4)$, compounds under study (from $5 \times 10^{-6}$ to $1 \times 10^{-3} \mathrm{M}$ ), $\mathrm{CuSO}_{4}(14$ $\mu \mathrm{M}), \mathrm{CH}_{3} \mathrm{CN}(2 \%)$, and $\mathrm{H}_{2} \mathrm{O}_{2}(50 \mathrm{mM})$ were incubated at $37^{\circ} \mathrm{C}$ for $45 \mathrm{~min}$. Control samples, free of polyphenol, contained ascorbic acid $(2.5 \mathrm{mM})$. Ethanol $(20 \mu \mathrm{L})$ was added to stop the oxidation. The samples were kept in an ice bath until analysis.

Analyses were conducted on an HPLC system (Merck/ Hitachi-LaChrom) equipped with a DAD detector (254 nm monitored) and a Waters Spherisorb ODS2 $(4.6 \times 250 \mathrm{~m}, 5$ $\mu \mathrm{m})$ column with precolumn. The mobile phase was composed of $85 \% \mathrm{KH}_{2} \mathrm{PO}_{4}(50 \mathrm{mM})$ and $15 \%$ methanol had a flow of $1 \mathrm{~mL} / \mathrm{min}$. The volume of sample injected was $20 \mu \mathrm{L}$.

Compounds were identified by comparison of their retention times with those of known standards. $2^{\prime}-\mathrm{dG}$ and 8-OH-2'-dG presented retention factors $(k)$ of 1.77 and 2.50, respectively). Areas of the samples were divided by the area of the control sample and the result was plotted.

\section{Determination of partition coefficients by derivative spectrophotometry}

Partition coefficients were determined at $\mathrm{pH} 7.4$ using micelles with different charged surfactants. Micelles were prepared by dissolution of a certain amount of the detergent (SDS, CTAB, or HDPC) in buffer (Hepes: $10.00 \mathrm{mM}, I=$ $0.1 \mathrm{M}(\mathrm{NaCl}), \mathrm{pH} 7.4)$. For each type of micelle, a series of solutions containing a fixed concentration of drug (approximately $50 \mu \mathrm{M}$ ) and increasing concentrations of surfactant $(0-1500 \mu \mathrm{M})$ were prepared.

\section{Ab initio MO calculations}

$\mathrm{Ab}$ initio molecular orbital calculations - full geometry optimization and calculation of the harmonic vibrational frequencies - were performed using the GAUSSIAN 98W program [26], within the density functional theory (DFT) approach. The widely employed hybrid method denoted as B3LYP [27-30], which includes a mixture of HF and DFT exchange terms and the gradient-corrected correlation functional of Lee et al. [31,32], as proposed and parameterized by Becke $[33,34]$, was used along with the double-zeta split valence basis sets $6-31 \mathrm{G}^{*}$ and $6-31 \mathrm{G}^{* *}[35,36]$.

Molecular geometries were fully optimized by the Berny algorithm, using redundant internal coordinates [37]: the bond lengths to within ca. $0.1 \mathrm{pm}$ and the bond angles to within ca. $0.1^{\circ}$. The final root-mean-square (rms) gradients were always less than $3 \times 10^{-4}$ Hartree.bohr $^{-1}$ or Hartree.rad ${ }^{-1}$. No geometrical constraints were imposed on the compounds under study.

\section{Results and discussion}

Numerous studies have shown that a number of flavonoids can interact with the oxidative processes taking place in vivo, such as lipid peroxidation, occurring in membranous phospholipids, and DNA oxidative damage, by scavenging chain-initiating oxygen radicals or chelating transition metal ions [38-41]. It is also known that an overload of copper or iron in humans leads to specific diseases, in which oxidative damage and an increased incidence of cancer are recognized. For example, Wilson's disease and genetic hemochromatosis are human conditions that proceed with disruption of copper or iron homeostasis [42]. It is also consensual that the study of the influence of dietary compounds on the oxidative damage induced by this type of transition metals is an important area of research, as the correlation of the data is a constructive tool for either a prophylactic or a therapeutic approach.

\section{Acidity constants}

For information on the electron-donating capacity of the flavonoid phenolic groups evaluation of the dissociation constants of the compounds was performed by potentiometry. Due to the limitations of this technique, related to the concentration and the solubility of the compounds, spectrophotometry was also applied. An automatic spectrophotometric system was used, which allows the recording of as many spectra as desired.

The acidity constants $(\log \beta)$ evaluated, and the $\mathrm{pH}$ range values used for their determination, for both catechin and taxifolin are presented in Table 1 . The values are means \pm standard deviation of at least 6 independent experiments. The $\mathrm{p} K \mathrm{a}$ values obtained for catechin $\left(\mathrm{p} K_{\mathrm{a} 1}=8.16 \pm 0.07, \mathrm{p} K_{\mathrm{a} 2}=\right.$ $9.20 \pm 0.09, \mathrm{p} K_{\mathrm{a} 3}=10.86 \pm 0.07$, and $\left.\mathrm{p} K_{\mathrm{a} 4}=11.50 \pm 0.20\right)$ are similar to those described in the literature [43]. For taxifolin the values of $\mathrm{pKa}$ were obtained by potentiometry and also determined by spectrophotometry, in order to validate the data and to find the $\mathrm{p} K_{\mathrm{a} 4}$. The results obtained were very similar for the first three $\mathrm{p} K \mathrm{a}\left(\mathrm{p} K_{\mathrm{a} 1}=6.68 \pm 0.02\right.$, $\mathrm{p} K_{\mathrm{a} 2}=8.89 \pm 0.04$, and $\mathrm{p} K_{\mathrm{a} 3}=10.95 \pm 0.09$ vs $\mathrm{p} K_{\mathrm{a} 1}=6.58 \pm$ $0.01, \mathrm{p} K_{\mathrm{a} 2}=8.81 \pm 0.10$, and $\mathrm{p} K_{\mathrm{a} 3}=10.70 \pm 0.23$, the values obtained by potentiometry and spectrophotometry, respectively). As noted previously, for this ligand the value of $\mathrm{p} K_{\mathrm{a} 4}=11.68 \pm 0.43$ was only obtained by spectrophotometry.

The distribution diagram of the different species as a function of $\mathrm{pH}$ for taxifolin is presented in Fig. 1A.

\section{Ab initio MO calculations}

Full geometry optimizations were performed for catechin and taxifolin. The most stable conformers are represented in Fig. 2. The effect of structural parameters on the overall stability of these molecules was investigated, namely: (i) the orientation of the phenolic hydroxyl groups, relative to the ring, and (ii) the relative position of the aromatic systems. 
Table 1

Acidity constants $(\log \beta)$ calculated for catechin and taxifonin, in aqueous solution ${ }^{\mathrm{a}}$

\begin{tabular}{|c|c|c|c|c|c|c|c|}
\hline \multirow[t]{3}{*}{ Ligand } & \multirow[t]{3}{*}{$\mathrm{p}$} & \multirow[t]{3}{*}{$\mathrm{r}$} & \multirow[t]{3}{*}{ Species } & \multirow[t]{3}{*}{$\Delta \mathrm{pH}$} & \multicolumn{3}{|l|}{$\log \beta$} \\
\hline & & & & & \multicolumn{2}{|l|}{ Potentiometry } & \multirow[t]{2}{*}{ Spectrophotometry } \\
\hline & & & & & (Superquad) & (Best) & \\
\hline \multirow[t]{5}{*}{ Catechin } & 1 & 1 & {$\left[\mathrm{H}_{4} \mathrm{~L}\right]$} & & & & \\
\hline & 1 & -1 & {$\left[\mathrm{H}_{3} \mathrm{~L}\right]^{-}$} & $7.4-11.0$ & $-8.16 \pm 0.07$ & $-8.25 \pm 0.08$ & \\
\hline & 1 & -2 & {$\left[\mathrm{H}_{2} \mathrm{~L}\right]^{2-}$} & $7.4-11.0$ & $-17.36 \pm 0.09$ & $-17.30 \pm 0.08$ & \\
\hline & 1 & -3 & {$[\mathrm{HL}]^{3-}$} & $7.4-11.0$ & $-28.22 \pm 0.07$ & $-28.35 \pm 0.09$ & \\
\hline & 1 & -4 & {$[\mathrm{~L}]^{4-}$} & $7.4-11.0$ & $-39.72 \pm 0.20$ & $-38.53 \pm 0.40$ & \\
\hline \multirow{5}{*}{ Taxifolin } & 1 & 1 & {$\left[\mathrm{H}_{4} \mathrm{~L}\right]$} & & & & \\
\hline & 1 & -1 & {$\left[\mathrm{H}_{3} \mathrm{~L}\right]^{-}$} & $3.1-10.8$ & $-6.68 \pm 0.02$ & $-6.50 \pm 0.02$ & 6.58 \\
\hline & 1 & -2 & {$\left[\mathrm{H}_{2} \mathrm{~L}\right]^{2-}$} & $3.1-10.8$ & $-15.57 \pm 0.04$ & $-15.15 \pm 0.07$ & 15.39 \\
\hline & 1 & -3 & {$[\mathrm{HL}]^{3-}$} & $3.1-10.8$ & $-26.52 \pm 0.09$ & $-26.47 \pm 0.09$ & 26.09 \\
\hline & 1 & -4 & {$[\mathrm{~L}]^{4-}$} & $9.0-11.0$ & - & - & 37.77 \\
\hline
\end{tabular}

${ }^{a}$ The symbols $p$ and $r$ are used in the program to indicate the stoichiometric coefficients associated with the possible equilibria in solution: $p$, for ligand and $r$, for protons.

The conformational behavior of this kind of compounds is mainly determined by electronic effects, as well as by the possibility of occurrence of $(\mathrm{C}) \mathrm{H}$. . . O intramolecular hydrogen bonds, which are of medium strength and directional interactions (with an expected preference for linearity), known to be relevant for the overall stability of this kind of system [44]. In taxifolin, such a close contact occurs between the carbonyl oxygen and a phenolic $\mathrm{H}$ atom $((\mathrm{C})=\mathrm{O} \ldots \mathrm{H}(\mathrm{O})$ distance equal to $170 \mathrm{pm}$ ) (Fig. 2). Moreover, the presence of the $\mathrm{C}=\mathrm{O}$ group in the central ring of the taxifolin molecule as opposed to catechin (Fig. 2) allows for a certain torsion of the phenyl substituent. This behavior may be responsible for the difference in the $\mathrm{p} K_{\mathrm{a}}$ values of the catechol group, previously determined for catechin and taxifolin:, $\mathrm{p} K_{\mathrm{a} 2}=9.20 \pm 0.09$ and $\mathrm{p} K_{\mathrm{a} 3}=10.86 \pm 0.07 \mathrm{vs} \mathrm{p} K_{\mathrm{a} 2}=8.89 \pm 0.04$ and $\mathrm{p} K_{\mathrm{a} 3}=$ $10.95 \pm 0.09$, respectively. For both flavonoids, the values
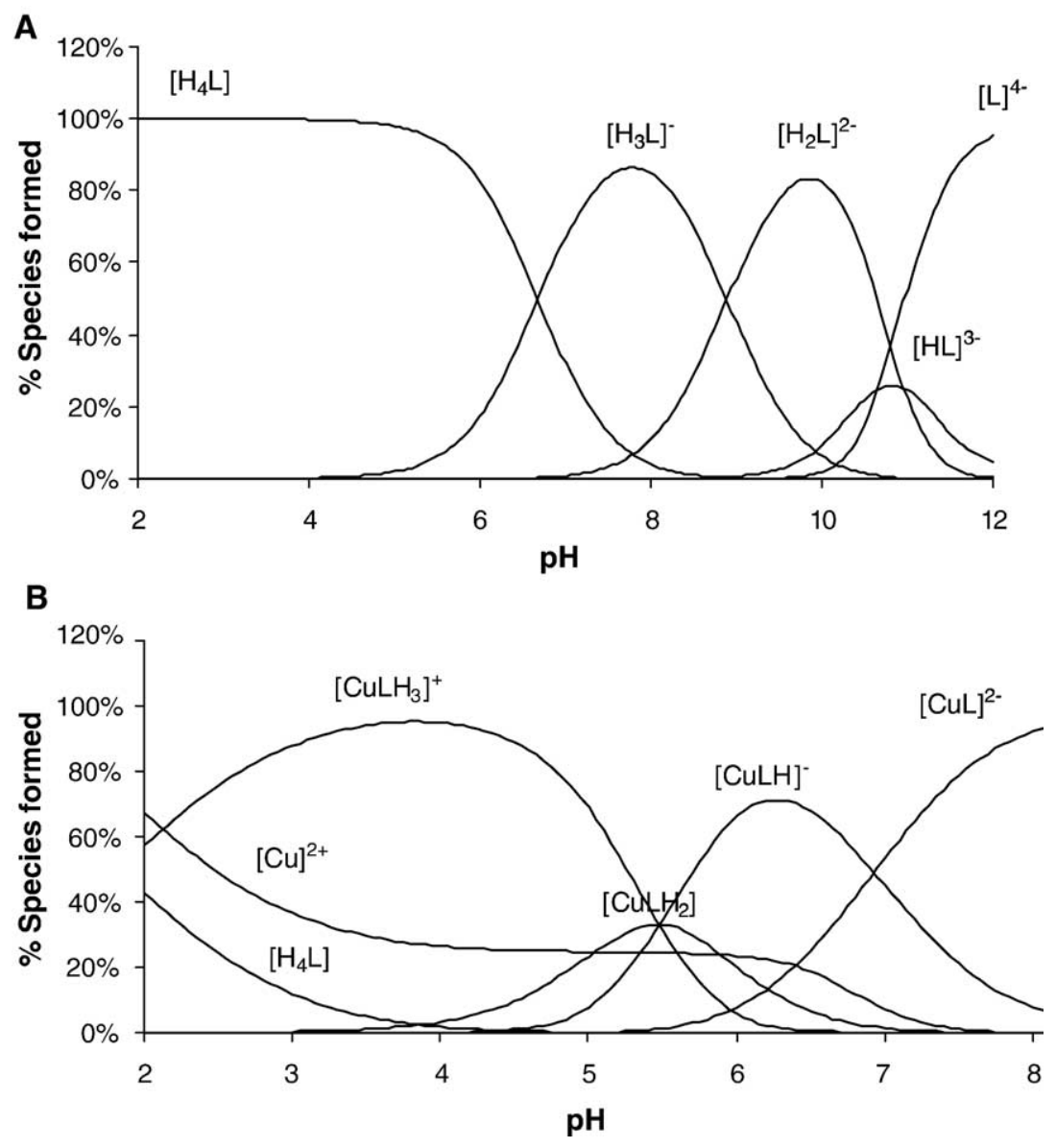

Fig. 1. Distribution diagrams of taxifolin (A) and $\mathrm{Cu}(\mathrm{II}) /$ taxifolin (B) species as a function of $\mathrm{pH}$. Simulation obtained with the HYSS program according to the equilibrium constants calculated for taxifolin $[\mathrm{H} 4 \mathrm{~L}]$ represents the fully protonated flavonoids. 
A
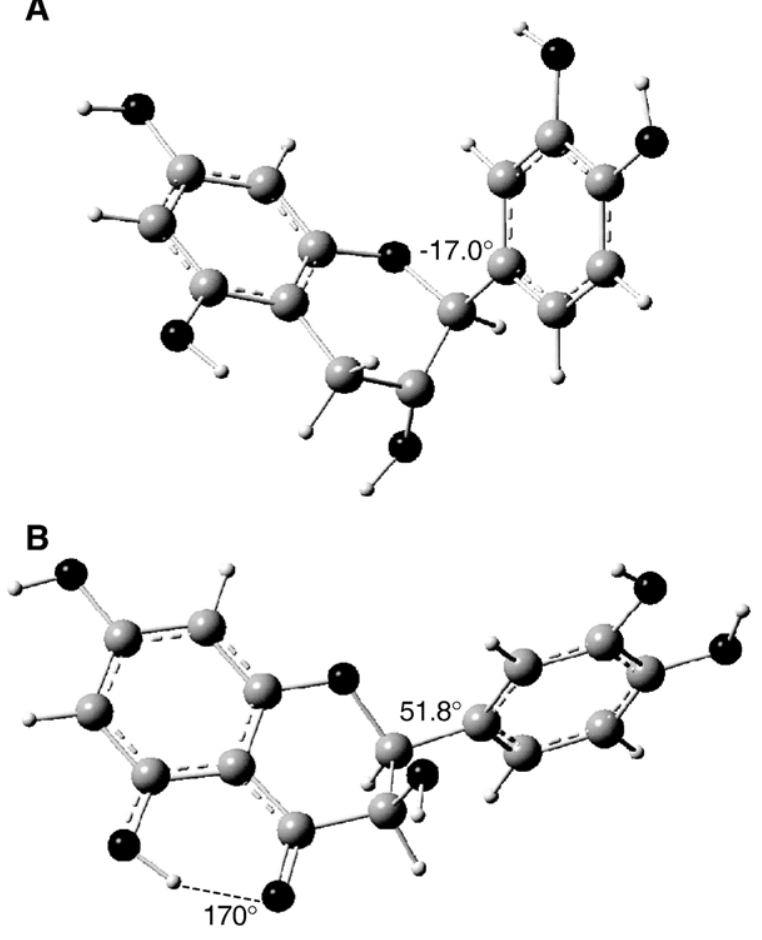

Fig. 2. Schematic representation of the calculated (B3LYP/6-31G**) minimum energy geometries for both catechin (A) and taxifolin (B) (Intramolecular hydrogen bonds are displayed. Distances in $\mathrm{pm}$; relative energies in $\mathrm{kJ} \mathrm{mol}^{-1}$ ).

obtained for the catechol group are not affected by the nature of the $\mathrm{C}$ ring substituents (Scheme 1).

By comparing the values of acidity constants determined for the two flavonoids studied, it should be stressed that the value of $\mathrm{p} K_{\mathrm{a} 1}$ of taxifolin $\left(\mathrm{p} K_{\mathrm{a} 1}=8.16 \pm 0.07\right)$ is smaller than the one obtained for catechin $\left(\mathrm{p} K_{\mathrm{a} 1}=6.68 \pm 0.02\right)$. This may be due to the presence of a carbonyl group at $\mathrm{C} 4$; indeed, this functional group induces an electronic shift, through a mesomeric effect, thus affecting the dissociation constant of the $\mathrm{O}-\mathrm{H}$ at $\mathrm{C}$. The value of $\mathrm{p} K_{\mathrm{a} 4}$ of taxifolin, in turn, is higher than the one calculated for catechin, on account of the presence of an additional effect: a hydrogen bound localized between the carbonyl at $\mathrm{C} 4$ and the phenolic group at C5 (Fig. 2).

According to the structural information currently obtained for the more stable conformers of catechin and taxifolin (Fig. 2 ), the experimental data, and what was found in the literature for analogous compounds [45-47], a deprotonation sequence can be proposed for catechin and taxifolin: ring $\mathrm{A}$ (7-OH), ring $\mathrm{B}\left(4^{\prime}-\mathrm{OH}, 3^{\prime}-\mathrm{OH}\right)$, ring $\mathrm{A}(5-\mathrm{OH})$, ring $\mathrm{C}(3-\mathrm{OH})$ (Scheme 1). Note that this proposal is not in agreement with the theoretical deprotonation sequence recently proposed for taxifolin and catechin [48-50].

\section{Formation constants}

The study of the interaction between flavonoids and transition metal ions is usually carried out by spectrophoto-
Table 2

Equilibrium constants $(\log \beta)$ calculated for copper (II)/catechin, in aqueous solution $^{\mathrm{a}}$

\begin{tabular}{lllllll}
\hline $\mathrm{p}$ & $\mathrm{q}$ & $\mathrm{r}$ & Species & \multicolumn{1}{l}{$\Delta \mathrm{pH}$} & \multicolumn{2}{l}{$\log \beta$} \\
\cline { 5 - 6 } & & & & \multicolumn{1}{l}{ Superquad } & \multicolumn{1}{c}{ Best } \\
\hline 1 & 1 & -2 & {$\left[\mathrm{CuLH}_{2}\right]$} & $3.0-10.6$ & $-7.91 \pm 0.2$ & $-7.63 \pm 0.3$ \\
1 & 1 & -3 & {$\left[\mathrm{CuLH}^{-}\right.$} & $3.0-10.6$ & $-15.88 \pm 0.4$ & $-15.58 \pm 0.5$ \\
1 & 1 & -4 & {$[\mathrm{CuL}]^{2-}$} & $3.0-10.6$ & $-25.27 \pm 0.4$ & $-24.95 \pm 0.7$ \\
\hline
\end{tabular}

${ }^{a}$ The symbols $\mathrm{p}, \mathrm{q}$, and $\mathrm{r}$ are used in the program to indicate the stoichiometric coefficients associated with the possible equilibria in solution: p, for ligand; q, for copper (II); and r, for protons.

metric analysis, allowing qualitative information on the process to be obtained. It is noteworthy that the characterization of flavonoid-metal complexes has also been performed through mass spectrometry, namely electrospray ionization tandem mass spectrometry [51-53].

In the present work, the spectrophotometric analysis was used in order to evaluate the flavonoid-chelate stability, which is of utmost relevance for understanding of the mechanisms of action of this type of compound. The formation constants $(\log \beta)$ obtained for the binary systems $\mathrm{Cu}(\mathrm{II}) /$ catechin and $\mathrm{Cu}(\mathrm{II}) /$ taxifolin, as well as the $\mathrm{pH}$ intervals in which the data were collected, are summarized in Tables 2 and 3.

For the binary system $\mathrm{Cu}(\mathrm{II}) /$ catechin, the model that best fits the data assumes the occurrence of an equilibrium in solution that corresponds to the formation of the following species: $\left[\mathrm{CuLH}_{2}\right],[\mathrm{CuLH}]^{-}$, and $[\mathrm{CuL}]^{2-}$. For the system $\mathrm{Cu}(\mathrm{II}) /$ taxifolin, in turn, the model that best fits the data considers the formation of the species: $\left[\mathrm{CuLH}_{3}\right]^{+}$, $\left[\mathrm{CuLH}_{2}\right],[\mathrm{CuLH}]^{-}$, and $[\mathrm{CuL}]^{2-}\left(\mathrm{L}^{4-}\right.$ representing the fully deprotonated flavonoid).

The formation constants obtained for the systems under study were $\mathrm{K}_{\mathrm{CuL}}^{\mathrm{Cu}}=14.45$ for catechin, and $\mathrm{K}_{\mathrm{CuL}}^{\mathrm{Cu}}=18.29$ for taxifolin. The value calculated for catechin is in a good agreement with the one reported in the literature $\left(\mathrm{K}_{\mathrm{CuL}}^{\mathrm{Cu}}=\right.$ 12.85 determined at $\left.30^{\circ} \mathrm{C}, I=0.1 \mathrm{M}\left(\mathrm{NaClO}_{4}\right)\right)$ [54]. For the other ligand, taxifolin, no values of formation constants were found in the literature. It can be stressed, for these experimental conditions, that taxifolin has a higher chelating ability than catechin.

Table 3

Equilibrium constants $(\log \beta)$ calculated for copper (II)/taxifolin, in aqueous solution ${ }^{\mathrm{a}}$

\begin{tabular}{lllllll}
\hline $\mathrm{p}$ & $\mathrm{q}$ & $\mathrm{r}$ & Species & $\Delta \mathrm{pH}$ & \multicolumn{2}{l}{$\log \beta$} \\
\cline { 5 - 6 } & & & & (Superquad) & \multicolumn{1}{l}{ (Best) } \\
\hline 1 & 1 & -1 & {$\left[\mathrm{CuLH}_{3}\right]^{+}$} & $3.1-5.6$ & $-1.60 \pm 0.1$ & $-1.54 \pm 0.1$ \\
1 & 1 & -2 & {$\left[\mathrm{CuLH}_{2}\right]$} & $3.3-5.9$ & $-7.07 \pm 0.1$ & $-7.47 \pm 0.6$ \\
1 & 1 & -3 & {$[\mathrm{CuLH}]^{-}$} & $3.3-5.9$ & $-12.55 \pm 0.9$ & $-12.89 \pm 0.9$ \\
1 & 1 & -4 & {$[\mathrm{CuL}]^{2-}$} & $3.2-6.0$ & $-19.48 \pm 0.3$ & $-22.63 \pm 0.9$ \\
1 & 2 & -4 & {$\left[\mathrm{Cu}_{2} \mathrm{~L}^{2}\right.$} & $3.1-6.0$ & $-14.51 \pm 0.3$ & $-13.84 \pm 0.8$ \\
2 & 1 & -4 & {$\left[\mathrm{CuL}_{2} \mathrm{H}_{4}\right]^{2-}$} & $3.4-5.6$ & $-14.10 \pm 0.3$ & $-13.76 \pm 0.4$ \\
\hline
\end{tabular}

${ }^{a}$ The symbols $p, q$, and $r$ are used in the program to indicate the stoichiometric coefficients associated with the possible equilibria in solution: $\mathrm{p}$, for ligand; $\mathrm{q}$, for copper (II); and r, for protons. 


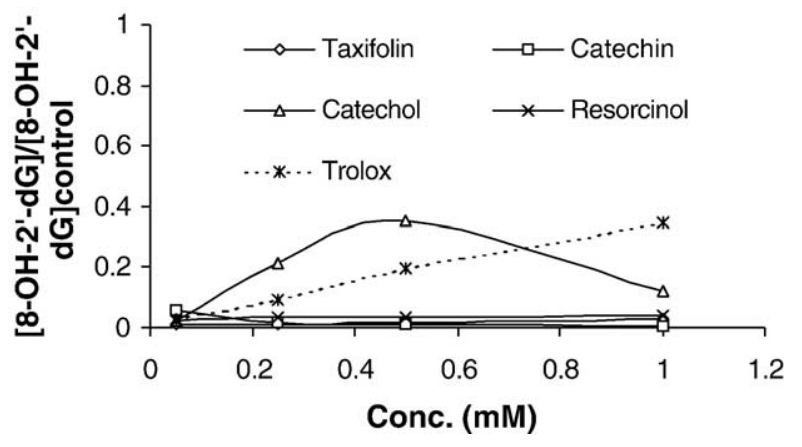

Fig. 3. Prooxidant profile of the phenolic compounds, catechin, taxifolin, resorcinol, and catechol, according to the levels of $\left[8-\mathrm{OH}-2^{\prime}-\mathrm{dG}\right]_{\text {sample area }}$ / $\left[8-\mathrm{OH}-2^{\prime}-\mathrm{dG}\right]_{\text {control area }}$ detected at $254 \mathrm{~nm}$ after HPLC separation.

The distribution diagram of the species of $\mathrm{Cu}(\mathrm{II}) /$ taxifolin system, as a function of $\mathrm{pH}$, is presented in Fig. 1B.

From the results currently obtained it can be deduced that the carbonyl group plays an important role in the acidity constants of flavonoids and in the complexation of transition metals. In turn, and as expected, the hydroxyl group in position 3 has little influence in the process, due to its spatial position.

The data obtained could be also important in understanding the possible implications of the copper-chelating properties of flavonoids in copper-mediated illnesses. Vestergaard et al. [55] investigated the redox properties of flavonoids using electrochemical methods (differential pulse voltammetry and cyclic voltammetry). It was concluded that the oxidation potential of flavonoids is influenced by the position and number of hydroxyl groups, apart from the presence of a carbonyl function [55]. These conclusions were supported by other reported electrochemical studies on the flavonoid family (including those of this study) [56-67]. They showed as well that the complex catechin/copper stayed redox-active through the shifting of the peak potentials after complexation with copper [55].

Furthermore, it was found that metal-flavonoid complexes are redox active and play a meaningful role in the antioxidant, anticancer, anti-inflammatory, and antibacterial properties of this kind of compounds, often being more active than the free flavonoids $[15,62,68-76]$.

\section{2'-Deoxyguanosine oxidation assay}

Flavonoids could act as prooxidants by reducing transition metals involved in the Fenton reaction and therefore induce oxidative damage. This capacity can be assessed by measuring the levels of 8-hydroxy-2'-deoxyguanosine, the oxidation product of $2^{\prime}-\mathrm{dG}$, after HPLC separation. The oxidation of $2^{\prime}-\mathrm{dG}$ is usually performed by an attack of the DNA base by hydroxyl radicals (HO.) produced by the reaction between a transition metal and $\mathrm{H}_{2} \mathrm{O}_{2}$. Reducing agents, like ascorbic acid [77] or other compounds, will then cycle metal to its reactive state. In this assay the flavonoids, catechin, and taxifolin as well as their counterparts resorcinol and catechol have been evaluated for their prooxidant activity. Results presented in Fig. 3 show that catechin, taxifolin, and resorcinol did not induce $2^{\prime}-\mathrm{dG}$ oxidation while a prooxidant behavior can be observed for catechol and trolox. It seems, therefore, that a catechol group can reduce $\mathrm{Cu}^{2+}$ to $\mathrm{Cu}^{+}$, allowing the catalysis of the Fenton reaction. On the other hand, the flavonoids could counterbalance this effect by scavenging the radicals formed.

Determination of partition coefficients using derivative spectroscopy

The octanol-water partition coefficient has traditionally been used to measure hydrophobicity, a parameter that could be correlated to the drug activity [78]. However, the octanol-water system is a good membrane model only when polar group interactions between the solute and the phospholipid bilayer are minimal or absent. Actually other models have been developed for compounds that can establish electrostatic interactions with the polar groups of the membrane surface [79]. Micellar systems are generally accepted to be suitable models for the study of membrane structure and properties [80].

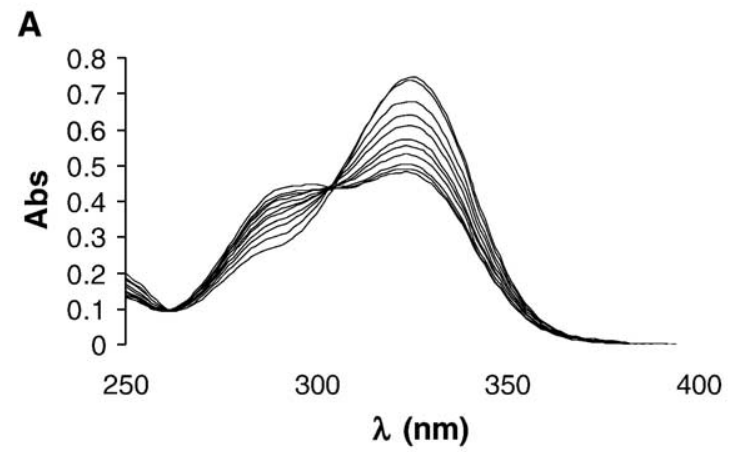

B

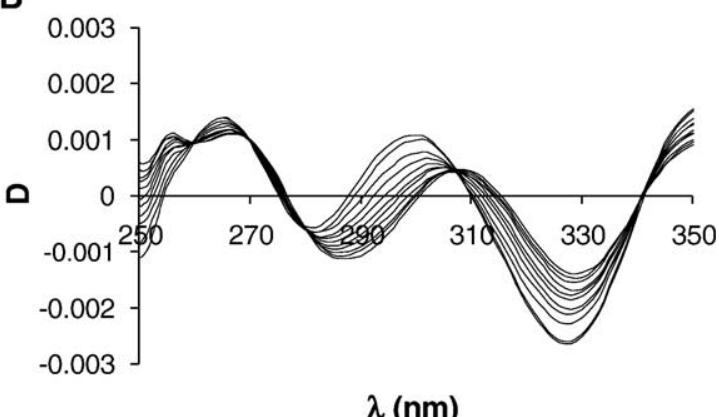

Fig. 4. Absorption spectra (A) and second-derivative spectra (B) of taxifolin at different HDPC concentrations $(0-1000 \mu \mathrm{M})$ recorded in saline buffer solutions (10 mM Hepes, $0.1 \mathrm{M} \mathrm{NaCl}, \mathrm{pH}$ 7.4). 
This study presents partition experiments in a micellar/ buffer system, since these experimental data will allow a much more satisfactory correlation between this parameter and biological behavior for the flavonoids investigated. The use of three differently charged surfactants (cationic, anionic, and zwitterionic) also allow assessment of the effect of electrostatic interactions on the partition coefficient.

The spectral characteristics of a solute are intrinsically related to the molecular interactions with its surrounding environment. In UV/Vis spectrophotometry of aqueous solutions of heterogeneous media, such as micelles, changes in the molar absortivity $(\varepsilon)$ or in the maximum wavelength of absorption $\left(\lambda_{\max }\right)$ can indicate that the molecule is interacting with the two media [80]. These changes can be used for the determination of the partition coefficient of the solute.

Derivative spectrophotometry, which eliminates the effect of background signals, enhances the ability to detect minor spectral features and allows the resolution of overlapped bands [81]. This technique has been used in this work, in order to determine the micelle/buffer partition coefficients of catechin and taxifolin in the presence of different surfactants (CTAB, SDS, and HDPC). For all cases, the absorbance of both drugs was found to decrease with an increase in surfactant concentration. Moreover, the spectra display isobestic points, which indicate that the drug exists in two states that yield different derivative spectra: the bound and the free drug [82]. Fig. 4 shows, as an example, the absorption spectra (A) and the derivative spectra (B) for taxifolin in different concentrations of HDPC.

Attending to the definition of $\log P$ expressed by

$\log P=\frac{[F]_{\mathrm{m}}}{[F]_{\mathrm{w}}}$

where $[F]_{\mathrm{m}}$ and $[F]_{\mathrm{w}}$ are the concentration of flavonoid in micellar and aqueous media, respectively. Considering that the absorbance of a micellar solution of the drug is $A_{\mathrm{f}}=A_{\mathrm{m}}+$ $A_{\mathrm{w}}$, where $A_{\mathrm{m}}$ and $A_{\mathrm{w}}$ are the micellar and aqueous absorbance of the drug, the following expression can be obtained [80],

$A_{\mathrm{f}} A_{\mathrm{w}}+\frac{\left(A_{\mathrm{m}}-A_{\mathrm{w}}\right) K p[\mathrm{M}]}{1+K p[\mathrm{M}]}$,

where $[\mathrm{M}]$ is the concentration of micellized detergent (equal to the total concentration of surfactant minus the critical micellar concentration $([C D]=[$ surfactant $]-\mathrm{cmc})$. The $\mathrm{cmc}$ values used for CTAB, SDS, and HDPC were 0.9,

Table 4

Partition coefficients $(\log P$ ) obtained for the flavonoids studied with the differently charged micelles - anionic (SDS), zwitternionic (HDPC), and cationic (CTAB)

\begin{tabular}{llll}
\hline & SDS & HDPC & CTAB \\
\hline Catechin & 0.81 & 3.15 & 3.60 \\
Taxifolin & 0.79 & 2.88 & 3.73 \\
\hline
\end{tabular}

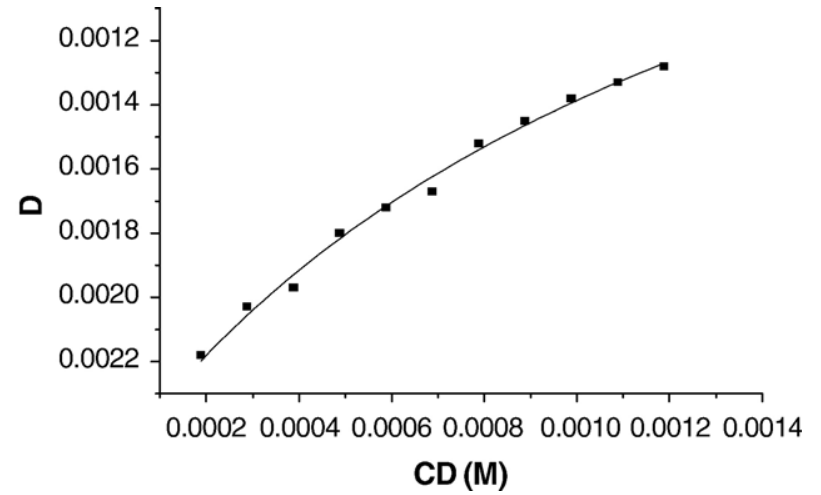

Fig. 5. Second-derivative values of absorption spectrum (D) at $\lambda=330 \mathrm{~nm}$ for taxifolin at different HDPC concentrations (CD). The curve representing the best fit (see text) generated the $\log P$ value for taxifolin.

1.4. and $10.3 \times 10^{-3} \mathrm{mM}$, respectively $[83,84]$. By fitting the equation to the experimental data, it is possible to calculate the partition coefficients. These results, expressed in $\log P$, are included in Table 4 . The second-derivative values at $\lambda=330 \mathrm{~nm}$ for taxifolin at different HDPC concentrations is presented in Fig. 5.

By comparing the experimental data determined for the three types of micellar systems, it is possible to verify that the partition process of the two flavonoids is different and highly dependent on the charge of the micelle. In fact, the values of $\log P$ obtained for the anionic surfactant (SDS) were the lowest, while those calculated for the cationic surfactant (CTAB) were the highest. For the SDS micelles, this is due to the repulsion between the negative form of the drug and the anionic surface of the surfactant, as opposed to the CTAB micelles, where an interaction may occur between the anionic drug and the cationic charged surfactant.

The values obtained for SDS were quite similar to those reported for the same compounds in an octanol/buffer system $[60,85]$, since this surfactant is negative and consequently the adsorption of flavonoids to the micelle surface is not significant. In turn, for the CTAB and HDPC micelles (respectively positive and zwitterionic surfactants) the $\log P$ values were found to be higher, due the electrostatic interaction with the micelle surface. Indeed, for charged compounds it is more appropriate to determine $\log P$ in systems, which are structurally similar to biomembranes, in order to obtain a good correlation between lipophilicity $(\log P)$ and biological activity.

\section{Concluding remarks}

It is well known that antioxidant and prooxidant activities have been ascribed to flavonoids and that the mutagenic and cocarcinogenic effects are frequently attributable to the prooxidant activity of this type of phenolic compounds [86-90]. Consequently, the determination of the physicochemical characteristics of these systems is of the utmost importance, since they could be the driving 
forces of either one or the other effect. Actually, knowledge of the dissociation constants and the metal complexation properties of dietary compounds may be relevant in view of gaining an insight into their antioxidant or prooxidant mechanisms [90]. For instance the possible interactions between the dietary flavonoids and the transition metals may play a crucial role in the in vivo oxidative damage processes. On the other hand the complexation of transition metals may also have an indirect effect on flavonoid activity, such as facilitating cell penetration or sparing the compound from inactivating metabolism, thus enhancing oxidative pathways. Furthermore, this type of ligand can also change the redox state of the metal, and consequently alter its bioavailability.

From an interdisciplinary point of view, only the combination of distinct research areas can allow achievement of the main goal: the design of new and efficient antioxidants, which can be used as therapeutic agents. On the other hand this type of study is the basis of successful QSAR determinations, since different parameters will be obtained from experimental data and not only from theoretical methods (that are not always the most accurate). In the near future, a suitable database for performing both SAR and QSAR studies will hopefully be built. Furthermore the physicochemical data gathered will contribute to highlight some currently accepted models (and mechanisms) of flavonoid-metal complexes.

In light of these considerations, the present work is clear evidence of the utmost need for performing structureproperty-activity relationship studies of the phenolic compounds present in the diet, aiming at understanding and correlating the biological data available so far. In addition, the physicochemical data obtained for these systems are of recognized importance in the prediction of metabolic pathways, as well as in the explanation of the activity of metabolites (which display some chemical similarity with the parent compound).

\section{References}

[1] Packer, L.; Hiramatsu, M.; Yoshikawa, T., eds. Antioxidant food supplements in human health. San Diego: Academic Press; 1999.

[2] Van Acker, S. A. B. E.; Bast, A.; Van der Vijgh, W. J. F. Structural aspects of antioxidant activity of flavonoids. In: Rice-Evans, C. A.; Packer, L., eds. Flavonoids in health and disease. New York: Dekker; 1998: 221-225.

[3] Bors, W.; Heller, W.; Michel, C.; Stettmaier, K. Flavonoids and polyphenols: chemistry and biology. In: Cadenas, E.; Packer, L., eds. Handbook of antioxidants. New York: Dekker; 1996.

[4] Formica, J. V.; Regelson, W. Food Chem. Toxicol. 33:1061-1080; 1995.

[5] Scott, B. C.; Butler, J.; Halliwell, B.; Aruoma, O. I. Free Radic. Res. Commun. 19:241-253; 1993.

[6] Teissedre, P. L.; Frankel, E. N.; Waterhouse, A. L.; Peleg, H.; German, B. G. J. Sci. Food Agric. 70:55-61; 1996.

[7] Cook, N. C.; Samman, S. Nutri. Biochem. 7:66-79; 1996.

[8] Ren, W.; Qiao, Z.; Wang, H.; Zhu, L.; Zhang, L. Med. Res. Rev. 23:519-534; 2003
[9] Youdim, K. A.; Shukitt-Hale, B.; Joseph, A. J. Free Radic. Biol. Med. 37:1683-1693; 2004.

[10] Husain, S. R.; Cillard, J.; Cillard, P. Phytochemistry 26:2489-2491; 1987.

[11] Bors, W.; Saran, M. Free Radic. Res. Commun. 2:289-294; 1987.

[12] Tsimogiannis, D. I.; Oreopoulou, V. Innov. Food Sci. Emerg. Technol. 5:523-528; 2004.

[13] Kehrer, J. P. Crit. Rev. Toxicol. 23 (1):21-48; 1993.

[14] Proudfoot, J. M.; Croft, K. D.; Puddey, I. B.; Beilin, L. J. Free Radic. Biol. Med. 23:720-728; 1997.

[15] Brown, J. E., et al. Biochem. J. 330:1173-1178; 1998.

[16] Borges, F.; Lima, J. L. F. C.; Pinto, I.; Reis, S.; Siquet, C. Helv. Chim. Acta 86:3081-3087; 2003.

[17] Silva, F. A. M.; Borges, F.; Guimarães, C.; Lima, J. L. F. C.; Matos, C.; Reis, S. J. Agric. Food Chem. 48:2122-2126; 2000.

[18] Silva, A. M. S.; Santos, C. M. M.; Cavaleiro, J. A. S.; Tavares, H. R.; Borges, F.; Silva, F. A. M. Magnetic resonance in food science. Cambridge: Royal Society of Chemistry; 2001: 110-116.

[19] Galati, G.; Sabzevari, O.; Wilson, J. X.; O’Brien, P. J. Toxicology 177:91-104; 2002.

[20] Cao, G.; Sofic, E.; Prior, R. L. Free Radic. Biol. Med. 22:749-760; 1997.

[21] Gažák, R.; Svobodová, A.; Psotová, J.; Sedmera, P.; Přikrylová, V.; Walterová, D.; Křen, V. Bioorg. Med. Chem. 12:5677-5687; 2004.

[22] Gran, G. Analyst 77:661-664; 1952.

[23] Gans, P.; Sabatini, A.; Vacca, A. J. Chem. Soc. Dalton 6:1195-1200; 1985.

[24] Martell, A. E.; Motekaitis, R. J. The determination and use of stability constants. New York: VCH; 1988

[25] Albert, A.; Serjeant, E. P. The determination of ionisation constants. London: Chapman and Hall; 1988.

[26] Frisch, M. J., et al. Gaussian 98, RevisionA.9. Pittsburgh, PA: Gaussian Inc.; 1998.

[27] Russo, T. V.; Martin, R. L.; Hay, P. J. J. Phys.Chem. 99: 17085-17087; 1995.

[28] Cotton, F. A.; Feng, X. J. Am. Chem. Soc. 119:7514-7520; 1997.

[29] Wagener, T.; Frenking, G. Inorg. Chem. 37:1805-1811; 1998.

[30] Cotton, F. A.; Feng, X. J. Am. Chem. Soc. 120:3387-3397; 1998.

[31] Lee, C.; Yang, W.; Parr, R. G. Phys. Rev. B 37:785-789; 1988.

[32] Miehlich, B.; Savin, A.; Stoll, H.; Preuss, H. Chem. Phys. Lett. 157: 200-206; 1989

[33] Becke, A. Phys. Rev. A 38:3098-3100; 1988.

[34] Becke, A. J. Chem. Phys. 98:5648-5652; 1993.

[35] Hariharan, P. C.; Pople, J. A. Theor. Chim. Acta 28:213-222; 1973.

[36] Francl, M. M.; Pietro, W. J.; Hehre, W. J.; Binkley, J. S.; Gordon, M. S.; DeFrees, D. J.; Pople, J. A. J. Chem. Phys. 77:3654-3665; 1982.

[37] Peng, C.; Ayala, P. Y.; Schlegel, H. B.; Frisch, M. J. Comp. Chem. 17:49-56; 1996.

[38] van Acker, F. A. A.; van den Berg, D.-J.; Tromp, M. N. J. L.; Griffion, D. H. Free Radic. Biol. Med. 20:331-342; 1996.

[39] Cao, G.; Sofic, E.; Prior, R. L. Free Radic. Biol. Med. 22:749-760; 1997.

[40] Rice-Evans, C.; Miller, N. J.; Paganga, G. Free Radic. Biol. Med. 20:933-956; 1996.

[41] Rezk, B. M.; Haenen, G. R. M. M.; Vijgh, W. J. F.; Bast, A. Biochem. Biophys. Res. Commun. 295:9-13; 2002.

[42] Halliwell, B.; Gutteridge, J. M. C. Free radicals in biology and medicine. London; Oxford: Science; 1999.

[43] Kennedy, J. A.; Munro, M. H. G.; Powell, H. K. J.; Porter, L. J.; Foo, L. Y. Aust. J. Chem. 37:885-892; 1984.

[44] Desiraju, G. R.; Steiner, G. R. T. The weak hydrogen bond in structural chemistry and biology, IUCR monographs on crystallography-9. London: Oxford Univ. Press; 1999, and refs. therein.

[45] Thompson, M.; Williams, C. R. Anal. Chim. Act 85:375-381; 1976.

[46] Jovanovic, S. V.; Steenken, S.; Tosic, M.; Marjanovic, B.; Simic, M. G. J. Am. Chem. Soc. 116:4846-4851; 1994. 
[47] Markham, K. R.; Bloor, S. J. Analysis and identification of flavonoids in practice. In: Rice-Evans, C. A.; Packer, L., eds. Flavonoids in health and disease. New York: Dekker; 1998: $1-30$.

[48] Martins, H. F. P.; Leal, J. P.; Fernandez, M. T.; Lopes, V. H. C.; Cordeiro, M. N. D. S. Am. Soc. Mass Spectrom. 15:848-861; 2004.

[49] Erkoç, S.; Erkoç, F.; Keskin, N. J. Mol. Struct. 631:141-146; 2003.

[50] Redrejo-Rodriguez, M.; Tejeda-Cano, A.; Pinto, M. C.; Macías, P. J. Mol. Struct. 674:121-124; 2004.

[51] Yamashita, N.; Tanemura, H.; Kawanishi, S. Mutat. Res. 425: $107-115 ; 1999$

[52] Fernandez, M. T.; Mira, M. L.; Florencio, M. H.; Jennings, K. R. J. Inorg. Biochem. 92:105-111; 2002.

[53] Bai, Y.; Song, F.; Chen, M.; Xing, J.; Liu, Z.; Liu, S. Anal. Sci. 20:1147-1151; 2004

[54] Takamura, K.; Sakamoto, M. Chem. Pharm. Bull. 26:2291-2297; 1978.

[55] Vestergaard, M.; Kerman, K.; Tamiya, E. Anal. Chim. Acta 538:273-381; 2005 .

[56] Hodnick, W. F.; Milosavljevic, E. B.; Nelson, J. H.; Pardini, R. S. Biochem. Pharmacol. 37 (13):2607-2611; 1988.

[57] Hendrickson, H. P.; Kaufman, A. D.; Lunte, C. E. J. Pharm. Biomed. Anal. 12 (3):325-334; 1994.

[58] Rapta, P.; Misik, V.; Stasko, A.; Vrabel, I. Free Radic. Biol. Med. 18 (5):901-908; 1995.

[59] Bors, W.; Michel, C.; Schikora, S. Free Radic. Biol. Med. 19 (1): $45-52 ; 1995$.

[60] Sergediene, E.; Jonsson, K.; Szymusiak, H.; Tyrakowska, B.; Rietjens, I. M. C. M.; Cenas, N. FEBS Lett. 462:393-396; 1999.

[61] Galati, G.; Chan, T.; Wu, B.; O'Brien, P. J. Chem. Res. Toxicol. 12:521-525; 1999.

[62] Kumamoto, M.; Sonda, T.; Nagayama, K.; Tabata, M. Biosc. Biotechnol. Biochem. 65 (1):126-132; 2001.

[63] Furuno, K.; Akasako, T.; Sugihara, N. Biol. Pharm. Bull. 25 (1): 19-23; 2002 .

[64] Brett, A. M. O.; Ghica, M.-E. Electroanalysis 15 (22):1745-1750; 2003.

[65] Janeiro, P.; Brett, A. M. O. Anal. Chim. Acta 518:109-115; 2004.

[66] Ghica, M.-E.; Brett, A. M. O. Electroanalysis 17 (4):313-318; 2005.

[67] Janeiro, P.; Brett, A. M. O. Electroanalysis 17 (9):733-738; 2005.

[68] Afanas'ev, B. I.; Ostrachovich, E. A.; Korkina, L. G. FEBS Lett. 425:256-258; 1998;

Afanas'ev, B. I.; Dorozhko, I. A.; Brodskii, V. A.; Kostyuk, A. V.; Potapovitch, I. A. Biochem. Pharmacol. 38:1-63; 1769.
[69] Korkina, L. G.; Afanas'ev, I. B. Antioxidant and chelating properties of flavonoids. In: Sies, M., ed. Antioxidants in disease mechanisms and therapy: advanced Pharmacology, vol. 38. San Diego: Academic Press; 1997: 151-163.

[70] Bodini, M. E.; Del Valle, M. A.; Tapia, R.; Leighton, F.; Gonzalez, L. Bol. Soc. Chil. Quim. 46 (3):309-317; 2001.

[71] Afanas'ev, I. B.; Ostrakhovitch, E. A.; Mikhal'chik, E. V.; Ibragimova, G. A.; Korkina, L. G. Biochem. Pharmacol. 61:677-684; 2001.

[72] Kostyuk, V. A.; Potapovich, A. I.; Vladykovskaya, E. N.; Korkina, L. G.; Afanas'ev, I. B. Arch. Biochem. Biophys. 385 (1):129-137; 2001.

[73] Song, Y.; Kang, J.; Wang, Z.; Lu, X.; Gao, J.; Wang, L. J. Inorg. Biochem. 91:470-474; 2002 .

[74] Moridani, M. Y.; Pourahmad, J.; Bui, H.; Siraki, A.; O’Brien, P. J. Free Radic. Biol. Med. 34 (2):243-253; 2003.

[75] Morel, I.; Cillard, P.; Cillard, J. Flavonoid-metal interactions in biological systems. In: Rice-Evans, C. A.; Packer, L., eds. Flavonoids in health and disease. New York: Dekker; 1998: 221-225.

[76] Kostyuk, V. A.; Potapovich, A. I.; Strigunova, E. N.; Kostyuk, T. V.; Afanas'ev, I. B. Arch. Biochem. Biophys. 428:204-208; 2004.

[77] Kasai, H.; Nishimura, S. Nucleic. Acid Res. 12:2137-2145; 1984.

[78] Hansch, C.; Dunn, W. J. J. Pharm. Sci. 61:1-19; 1972.

[79] Betageri, G. V.; Rogers, J. A. Int. J. Pharm. 46:95-102; 1988.

[80] Kitamura, K.; Imayoshi, N.; Goto, T.; Shiro, H.; Mano, T.; Nakai, Y. Anal. Chim. Acta 304:101-106; 1995.

[81] Hagga, M.; Fleming, R. J. Pharm. Pharm. 25:159-160; 1973.

[82] Kitamura, K.; Imayoshi, N. Anal. Sci. 8:497-501; 1992.

[83] Araujo, P. S.; Rosseneu, M. Y.; Kremer, J. M. H.; Zoelen, J. J.; Haas, G. H. Biochemistry 18:580-586; 1979.

[84] Mukerjee, P.; Mysels, K. J.; eds. Critical micelle concentration of aqueous surfactant systems. National Standard reference data system, 1971: 51-57.

[85] Kajiya, K.; Hojo, H.; Suzuki, M.; Nanjo, F.; Kumazawa, S.; Nakayama, T. J. Agric. Food Chem. 52:1514; 2004.

[86] Azam, S.; Hadi, N.; Khan, N. U.; Hadi, S. M. Toxicol. In Vitro 18:555-561; 2004.

[87] Yen, G.-C.; Duh, P.-D.; Tsai, H.-L.; Huang, D.-L. Biosc. Biotechn. Biochem. 67:1215-1222; 2003.

[88] Ohshima, H.; Yoshie, Y.; Auriol, S.; Gilbert, I. Free Radic. Biol. Med. 25:1057-1065; 1998.

[89] Rapta, P.; Misík, V.; Stasko, A.; Vrábel, I. Free Radic. Biol. Med. 18:901-908; 1995.

[90] Moran, J. F.; Klucas, R. V.; Grayer, R. J.; Abian, J.; Becana, M. Free Radic. Biol. Med. 22:861-870; 1997. 